\title{
Volcanism in the Afar Rift sustained by decompression melting with minimal plume influence
}

\author{
Catherine A. Rychert ${ }^{1 \star}$, James O. S. Hammond ${ }^{2}$, Nicholas Harmon ${ }^{1}$, J. Michael Kendall ${ }^{3}$, Derek Keir ${ }^{1}$, \\ Cynthia Ebinger ${ }^{4}$, Ian D. Bastow ${ }^{3}$, Atalay Ayele ${ }^{5}$, Manahloh Belachew ${ }^{4,5}$ and Graham Stuart ${ }^{6}$
}

\begin{abstract}
Continental breakup is caused by some combination of heating and stretching, ${ }^{1,2}$. The Afar Rift system in Africa is an example of active continental rifting, where a mantle plume probably weakened the lithosphere through thermal erosion and magma infiltration. However, the location and degree of plume influence today are debated ${ }^{2,3}$. Here we use seismic Sto- $P$ receiver functions to image the mantle structure beneath Afar. We identify the transition between the lithosphere and underlying asthenosphere at about $75 \mathrm{~km}$ depth beneath the flanks of the continental rift. However, this boundary is absent beneath the rift itself and we instead observe a strong increase in seismic velocities with depth, at about $75 \mathrm{~km}$. We use geodynamic modelling to show that the velocity increase at this depth is best explained by decompression melting of the mantle in the absence of a strong thermal plume. So, although the absence of mantle lithosphere beneath the rift implies a plume may have once been active, we conclude that the influence of a thermal plume directly beneath Afar today is minimal.
\end{abstract}

Rifting processes are key to our understanding of continent stability and a fundamental aspect of plate tectonics. However, the mechanism by which continental lithosphere initially breaks apart and its continued evolution to seafloor spreading are not well understood. The Afar triple junction subaerially exposes the transition from continental rifting to seafloor spreading and is therefore the ideal study locale of continental breakup processes. It is the intersection of the southern Red Sea Rift (RSR), Gulf of Aden Rift (GOA), and Main Ethiopian Rift (MER). Early stages of seafloor spreading occur in the Asal Rift, the onshore westward extension of the GOA (initiated $\sim 35$ million years (Myr) ago) as well as the RSR (initiated $\sim 28 \mathrm{Myr}$ ago; ref. 4 ). The MER, the youngest arm, initiated rifting $\sim 18 \mathrm{Myr}$ ago, propagated north reaching the RSR at $10^{\circ} \mathrm{N} \sim 11 \mathrm{Myr}$ ago, overprinting Red Sea structures ${ }^{5}$. Magmatic rifting of the continental lithosphere occurs to the south in northern Tanzania and southern Kenya ${ }^{6}$. Lithospheric weakening and stretching through the influx of hot plume material is one mechanism that has been presented to explain rift initiation in magmatic rift zones such as Afar ${ }^{1,2}$. However, the location(s) and degree of influence of plume material in the Afar Rift system at present is debated (for example, refs 2,3). Knowing the thickness of the lithosphere and the depth to the onset of decompression melting is important to our understanding of the thermal structure of the mantle, the degree of plume influence and the deformation history of the lithosphere ${ }^{7,8}$. Several recent seismic studies found evidence for melt in the crust and upper mantle beneath the rift based on high ratios of the $\mathrm{P}$-wave velocity to the $\mathrm{S}$-wave velocity $\left(V_{\mathrm{p}} / V_{\mathrm{s}}\right.$ ratios), velocities $5-10 \%$ slower than the global average and anisotropy ${ }^{9-13}$. However, precise determination of lithospheric thickness and depth of melting have proved challenging with existing seismic methodologies. Indeed, whether or not a rigid mantle lithosphere exists beneath rifts has remained relatively unknown until this point, fueling controversy and hampering predictive models of magmatic rifting ${ }^{1,7}$.

Here two S-to-P (Sp) receiver-function techniques image lithospheric structure and confirm robust features beneath the Afar triple junction and surrounding regions. Conversion-point binning with simultaneous deconvolution in the frequency domain ${ }^{14,15}$ is used for detailed modelling of robust features. Extended multitaper deconvolution ${ }^{16}$ followed by migration and stacking ${ }^{9,17}$ confirms robust features and gives a three-dimensional view of lithospheric structure. High-resolution coverage is provided by three data sets (Fig. 1; Supplementary Information) ${ }^{9}$.

The most significant feature besides the Moho is a strong negative phase at a mean depth of $77 \pm 4 \mathrm{~km}$ on the western flanks of the rift (Fig. 2). Little variability in depth is observed with the exception of the flood basalt region on the western flank where the discontinuity shallows from $\sim 80$ to $\sim 60 \mathrm{~km}$ (Fig. 2 ). Furthermore, a striking variation in the character of waveforms from the flank to the rift exists in the $75 \pm 20 \mathrm{~km}$ depth range in both methodologies (Figs 2,3). Beneath the rift, no strong negative phase is imaged, rather a subtle but persistent positive phase is observed at a mean depth of $74 \pm 4 \mathrm{~km}$ (Fig. 3). The polarity of significant phases between $75 \pm 20 \mathrm{~km}$ depth is strongly correlated with the location of the rift (Fig. 1).

The depth of the large negative phase beneath the rift flank is coincident with the base of the seismically fast lid from surface waves and body waves, $\sim 50-80 \mathrm{~km}$ beneath the flank regions, and is therefore the lithosphere-asthenosphere boundary ${ }^{12,18}$ (LAB), in agreement with previous single-station receiver-function results (see Supplementary Information). The lack of a strong negative LAB phase beneath the rift indicates that the mantle lithosphere has been replaced by upwelling asthenosphere. This is supported by previously reported seismic-velocity models that lack a velocity

\footnotetext{
${ }^{1}$ National Oceanography Centre Southampton, Ocean and Earth Sciences, University of Southampton, Southampton SO14 3ZH, UK, ${ }^{2}$ Department of Ocean and Earth Science and Engineering, Imperial College London, South Kensington Campus, London SW7 2AZ, UK, ${ }^{3}$ Department of Earth Sciences, University of Bristol, Bristol BS8 1RJ, UK, ${ }^{4}$ Department of Earth and Environmental Sciences, University of Rochester, Rochester, New York 14627, USA, ${ }^{5}$ Institute of Geophysics Space Science and Astronomy, Addis Ababa University, Addis Ababa 1176, Ethiopia, ${ }^{6}$ School of Earth and Environment, University of Leeds, Leeds LS2 9JT, UK. *e-mail: c.rychert@soton.ac.uk.
} 


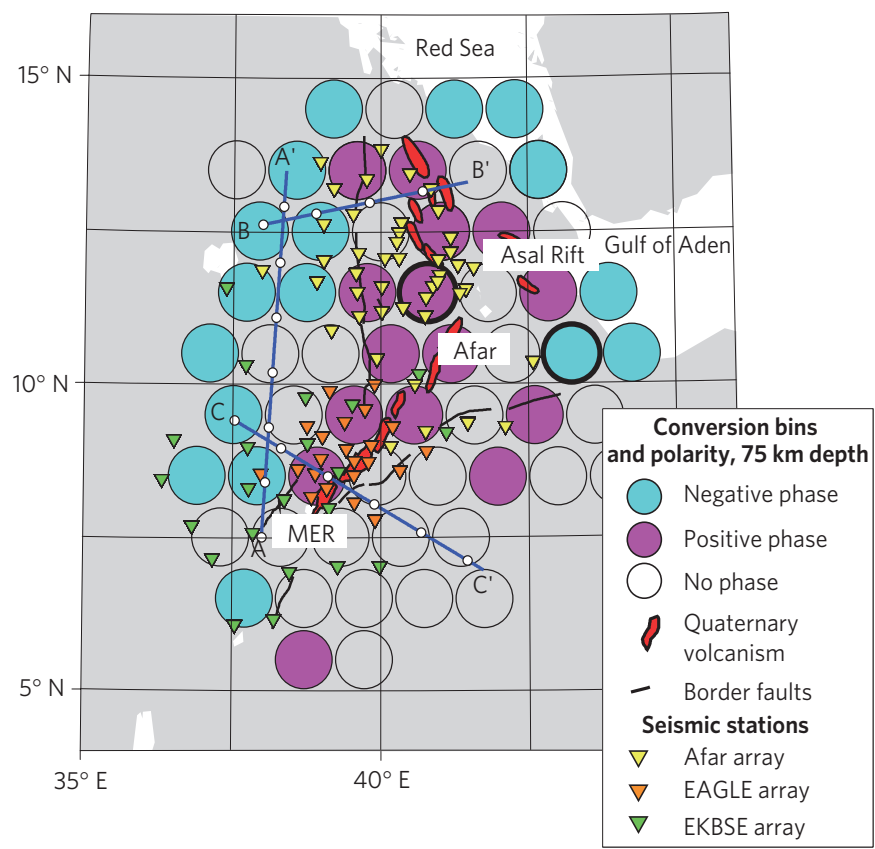

Figure 1 | Stations, bins and phase polarity at $75 \mathrm{~km}$ depth from simultaneous deconvolution. Stations (inverted triangles) include a new UK/US-led deployment (yellow), Ethiopia Afar Geoscientific Lithospheric Experiment (EAGLE; orange) and Ethiopia/Kenya Broadband Seismic Experiment (EKBSE; green). Bin locations with $>10$ traces at $75 \mathrm{~km}$ depth are plotted (circles). Example bins (Fig. 3) are circled in bold. Polarity of significant phases at $75 \pm 20 \mathrm{~km}$ depth is indicated by bin colour, blue (negative) and pink (positive). Red areas show the Quaternary-Recent volcanic segments. Black lines show border faults separating Afar from western and eastern plateaux. Blue lines indicate cross-section locations (Fig. 2).

inversion beneath the rift ${ }^{12,18}$. Indeed, plate-reconstruction models require the lid to be stretched by factors of three and two beneath Afar and the MER, respectively ${ }^{19}$, which is roughly explained by the absence of subcrustal lithosphere beneath the rift ${ }^{7}$. In other words, the $75-\mathrm{km}$-thick lithospheric lid on the flank is about three times the $\sim 25-\mathrm{km}$-thick crustal lid beneath much of Afar and about twice the $\sim 35-37-\mathrm{km}$-thick crustal lid beneath the MER (ref. 9).

The transition from flank to rift is abrupt, occurring over less than $\sim 50 \mathrm{~km}$ (Figs 1, 2). A sloped LAB is not imaged at the transition as it is too steep to be imaged by $\mathrm{Sp}$, which loses resolution at slopes $>\sim 20^{\circ}$ based on critical angle calculations. The abrupt transition indicates that the lithospheric lid is not purely thermally defined (Fig. 3, 1,200 ${ }^{\circ} \mathrm{C}$ isotherm versus interpreted transition).

Synthetic waveform modelling also indicates that a mechanism in addition to temperature is required. For example, beneath the flank the data are best fit by an $11 \%$ velocity drop at $77 \mathrm{~km}$ depth (Fig. 3). A small amount of partial melting in the asthenosphere is probably required to explain the large, sharp velocity drop and therefore the boundary probably represents a barrier in permeability ${ }^{20}$. Beneath the rift a strong velocity increase with depth near $75 \mathrm{~km}$ is required. For example, the example bin is best fit by a $8 \%$ velocity increase at $66 \mathrm{~km}$ depth and an additional $5 \%$ velocity increase at $51 \mathrm{~km}$ depth, or about $13 \%$ over a depth range of $\sim 15 \mathrm{~km}$ (Fig. 3). Models where only a Moho is included fit the data significantly worse than the best-fitting synthetic, that is, outside error bars (dashed blue line versus red line in Fig. 3). Indeed, no model fits the data unless it has a strong, sharp velocity increase in the $75 \mathrm{~km}$ depth range (see Supplementary Information and Fig. S1). At the very least two $4 \%$ increases, or a total of $8 \%$, are required to match the limits of the bootstrap errors.
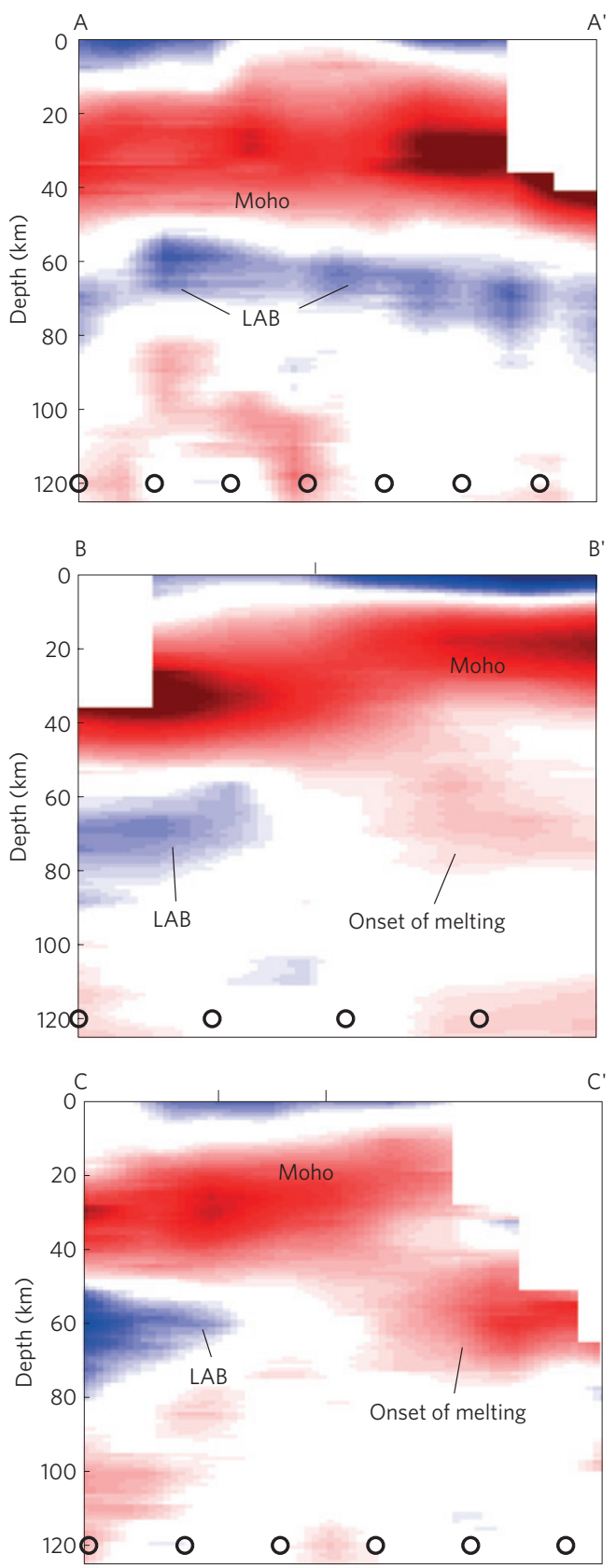

Figure 2 | Cross-sections from extended multitaper and migration. Positive polarity amplitudes are in red (velocity increase with depth) and negative polarity amplitudes are in blue (velocity decrease with depth). Black circles at $120 \mathrm{~km}$ depth show $100 \mathrm{~km}$ distance intervals. Ticks along the top of the panels show border faults. Discontinuity interpretations are labelled: crust-mantle (Moho); LAB; onset of decompression melting (onset of melting). Bins with $<10$ waveforms are not shown (white boxes). Only major features are interpreted. Minor features come from noise or sensitivity to off-axis structure.

The velocity increase beneath the rift matches predictions from geodynamic modelling. Numerical simulations of mantle flow, temperature and melting beneath a slow-rifting lithosphere with $1 \%$ melt retention find a rapid decrease in melt volume with depth, $1.0 \%$ to $0.0 \%$ over a depth range of $<15 \mathrm{~km}$ (Fig. 3 ), as melt percolates through the melt triangle in the upwelling zone (also see Supplementary Information and Figs S2, S3). The decrease in melt percentage with depth produces a sharp velocity increase with depth that agrees with both the depth $(75 \mathrm{~km})$ and magnitude 


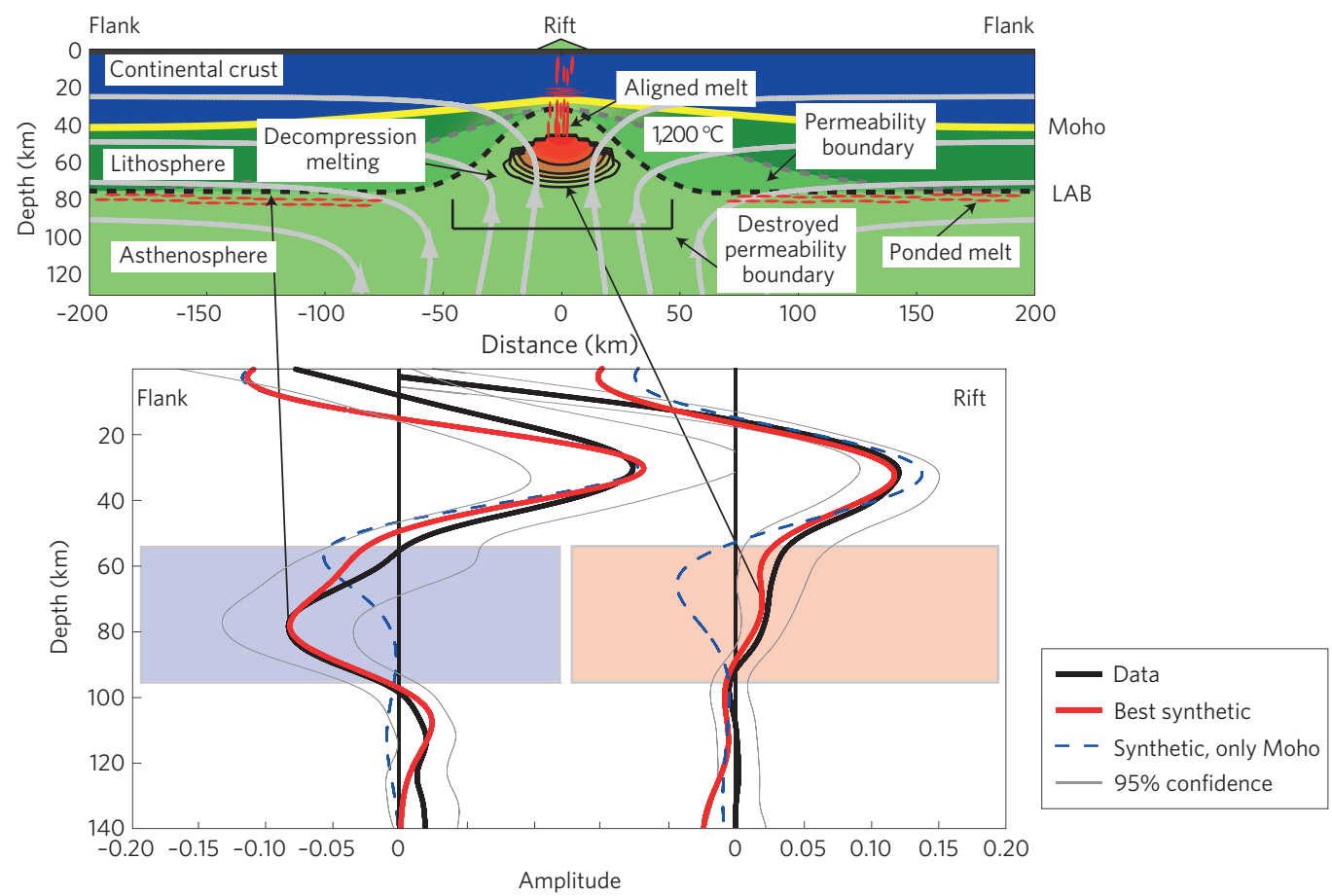

Figure 3 | Summary and waveform modelling. Waveform modelling (bottom panel) shows data (black lines) from two example bins with $95 \%$ confidence limits from bootstrap (grey lines). Synthetic waveforms are shown for the best model (red lines) and a model with only a Moho discontinuity (blue dashed lines). Blue and red shaded regions highlight the depth range of interest. Schematic (top panel) shows geodynamic modelling and interpretation. Moho (yellow line), flow lines (grey), $1,200^{\circ} \mathrm{C}$ isotherm (dashed grey line) and interpreted permeability barrier (dashed black line) with underlying melt (red dashes) are shown. Previously suggested crustal melt is also shown (red ovals). Melt percentage contoured at $0.2 \%$ intervals in the region of decompression melting beneath the rift is shown for melt volumes $0 \%$ (green) to 1\% (red).

(8\% velocity increase) of the observed phase (Fig. 3). One per cent melt retention assumes strong melt-buoyancy effects, which have been previously proposed for mid-ocean ridges ${ }^{21}$ and are also probably required beneath Afar. Previous surface-wave, body-wave and receiver-function results have similarly interpreted very slow velocities and very high $V_{\mathrm{p}} / V_{\mathrm{s}}$ values as significant amounts of shallow melting $9,11,12$.

The depth of the positive phase/inferred base of the melt triangle provides a powerful constraint on the thermal structure beneath the rift and therefore the presence or absence of a mantle plume today. Mantle potential temperatures of $1,350-1,400{ }^{\circ} \mathrm{C}$ give velocity increases centred at $65-85 \mathrm{~km}$ depth, that is, within the range of seismic results. But increased potential temperatures expected for a plume, that is, temperatures $\geq 1,450^{\circ} \mathrm{C}$, would increase the expected depth of melting to $>100 \mathrm{~km}$ (ref. 22; Supplementary Figs S2, S3), outside our error bars for the depth of the discontinuity. Therefore, no plume is required directly beneath the rift today and volcanism by adiabatic decompression melting can explain the observations.

Adiabatic decompression melting is commonly accepted beneath mid-ocean ridges, but is more difficult to reconcile beneath Afar where models predict that cool continental temperatures and slow continental rifting $\left(\sim 6-20 \mathrm{~mm} \mathrm{yr}^{-1}\right)$ lead to negligible melt production $^{23,24}$. Therefore, a plume is often invoked to explain active volcanism in Afar today. For example, low seismic velocities in the mantle beneath the rift $^{11}$, seismic imaging of a thin or non-existent lithosphere ${ }^{18}$ and geochemical estimates for potential temperatures ${ }^{25}$ beneath the rift have all been used to argue for a thermal anomaly, that is, a plume source directly beneath Afar at present.

Our alternative model is one in which a direct thermal plume influence no longer exists, but volcanism occurs through decompression melting enhanced by melt-buoyancy effects. Melt buoyancy not only explains the large melt retention required to explain the velocity profile beneath the rift and seismic velocities from previous results, but also prolongs active volcanism past the influence of an active plume source.

This model is supported by a number of other observations, for example, Africa has moved $>500 \mathrm{~km}$ northwards in a hotspot reference frame, away from the location where the plume-related flood basalt magmatism occurred $\sim 30 \mathrm{Myr} \mathrm{ago}^{26}$. Furthermore, our predicted range of potential temperatures $\left(1,350-1,400^{\circ} \mathrm{C}\right)$ agrees with the range from geochemistry $\left(1,370-1,490^{\circ} \mathrm{C}\right.$; ref. 25$)$ and also from mid-ocean ridge basalts $\left(1,350-1,450^{\circ} \mathrm{C}\right.$; see Supplementary Information). Although the upper ends of these ranges have been interpreted as warmed mantle, possibly owing to regional plume influence, they are certainly too cold to be attributed to a direct plume influence, which would be much hotter $\left(1,500-1,700^{\circ} \mathrm{C}\right.$; see Supplementary Information). Indeed, petrologic estimates for the depth of melting in Afar (70-90 km; ref. 27) agree with the depth of our observed seismic discontinuity $(\sim 75 \mathrm{~km})$ and therefore the lack of a strong thermal plume signature directly beneath Afar. Low velocities beneath the rift extending to $\sim 200 \mathrm{~km}$ depth compared with surrounding regions ${ }^{11}$ may be explained by a low-viscosity asthenospheric channel that feeds the rift, creating an influx of material that is warmer than surrounding regions, but certainly no strong thermal plume ${ }^{28}$. Although Afar is very different from a midocean ridge, this type of model has been used to describe similar velocity structures (Afar and the East Pacific Rise are similar at $75 \mathrm{~km}$ depth in global velocity models ${ }^{10}$ ) and relatively low mantle potential temperatures beneath the East Pacific Rise ${ }^{28}$. Lateral asthenospheric flow has also been invoked to explain diachronous volcanism and geochemical variations beneath $\mathrm{Afar}^{3}$.

Although we require no thermal plume signature directly beneath present-day Afar, a plume has certainly played an important role in the rifting history. A plume signature has been observed in lavas from $\sim 30 \mathrm{Myr}$ ago in flood basalts on the 
Ethiopian plateau ${ }^{27}$. The plume was required to initially weaken the rigid lithosphere lid and initiate rifting ${ }^{1,29}$. The influence of the plume was large. Numerical models indicate that a large initial signature is required to produce flood basalts, without which volcanism would also shut off within a few million years ${ }^{23}$. Melt buoyancy may enhance focused upwelling and melting beneath the rift, extending volcanism for an additional $\sim 5-6 \mathrm{Myr}$ past the influence of a strong thermal plume signature ${ }^{21}$. Therefore, active volcanism in Afar today may be explained by a plume signature that faded sometime in the past $\sim 5 \mathrm{Myr}$ followed by continued volcanism from melt-buoyancy effects. If plume material reaches Afar, we suggest that it has been cooled and arrives from a distant source, through horizontal channelized asthenospheric flow ${ }^{3,30}$.

Received 23 November 2011; accepted 23 March 2012; published online 29 April 2012

\section{References}

1. Buck, W. R. in Rheology and Deformation of the Lithosphere at Continental Margins (eds Karner, G. D., Taylor, B., Driscoll, N. W. \& Kohlstedt, D. L.) 1-30 (Columbia Univ. Press, 2004).

2. White, R. \& Mckenzie, D. Magmatism at rift zones-the generation of volcanic continental margins and flood basalts. J. Geophys. Res. 94, 7685-7729 (1989).

3. Ebinger, C. J. \& Sleep, N. H. Cenozoic magmatism throughout east Africa resulting from impact of a single plume. Nature 395, 788-791 (1998).

4. Prodehl, C. \& Mechie, J. Crustal thinning in relationship to the evolution of the Afro-Arabian rift system-a review of seismic-refraction data. Tectonophysics 198, 311-327 (1991)

5. Wolfenden, E., Ebinger, C., Yirgu, G., Deino, A. \& Ayalew, D. Evolution of the northern Main Ethiopian Rift: Birth of a triple junction. Earth Planet. Sci. Lett. 224, 213-228 (2004).

6. Weeraratne, D. S., Forsyth, D. W., Fischer, K. M. \& Nyblade, A. A. Evidence for an upper mantle plume beneath the Tanzanian craton from Rayleigh wave tomography. J. Geophys. Res. 108, 2427-2444 (2003).

7. Huismans, R. \& Beaumont, C. Depth-dependent extension, two-stage breakup and cratonic underplating at rifted margins. Nature 473, 74-78 (2011).

8. Lekic, V., French, S. \& Fischer, K. M. Lithospheric thinning beneath rifted regions of southern California. Science 334, 783-787 (2011).

9. Hammond, J. O. S. et al. The nature of the crust beneath the Afar triple junction: Evidence from receiver functions. Geochem. Geophys. Geosyst. 12, Q12004 (2011).

10. Kustowski, B., Ekstrom, G. \& Dziewonski, A. M. Anisotropic shear-wave velocity structure of the Earth's mantle: A global model. J. Geophys. Res. 113, B06306 (2008).

11. Bastow, I. D., Nyblade, A. A., Stuart, G. W., Rooney, T. O. \& Benoit, M. H. Upper mantle seismic structure beneath the Ethiopian hot spot: Rifting at the edge of the African low-velocity anomaly. Geochem. Geophys. Geosyst. 9, Q12022 (2008).

12. Fishwick, S. Surface wave tomography imaging of the lithosphere-asthenosphere boundary beneath central and southern Africa? Lithos 120, 63-73 (2010).

13. Kendall, J. M., Stuart, G. W., Ebinger, C. J., Bastow, I. D. \& Keir, D. Magma-assisted rifting in Ethiopia. Nature 433, 146-148 (2005).

14. Bostock, M. G. Mantle stratigraphy and evolution of the Slave province. J. Geophys. Res. 103, 21183-121200 (1998).

15. Rychert, C. A., Rondenay, S. \& Fischer, K. M. P-to-S and S-to-P imaging of a sharp lithosphere-asthenosphere boundary beneath eastern North America. J. Geophys. Res. 112, B08314 (2007).
16. Helffrich, G. Extended-time multitaper frequency domain cross-correlation receiver-function estimation. Bull. Seismol. Soc. Am. 96, 344-347 (2006).

17. Angus, D. A. et al. Stratigraphy of the Archean western Superior province from $\mathrm{P}$ - and S-wave receiver functions: Further evidence for tectonic accretion? Phys. Earth Planet. Inter. 177, 206-216 (2009).

18. Dugda, M. T., Nyblade, A. A. \& Julia, J. Thin lithosphere beneath the Ethiopian plateau revealed by a joint inversion of Rayleigh wave group velocities and receiver functions. J. Geophys. Res. 112, B08305 (2007).

19. Eagles, G., Gloaguen, R. \& Ebinger, C. Kinematics of the Danakil microplate. Earth Planet. Sci. Lett. 203, 607-620 (2002).

20. Holtzman, B. K. \& Kendall, J. M. Organized melt, seismic anisotropy, and plate boundary lubrication. Geochem. Geophys. Geosyst. 11, Q0AB06 (2010).

21. Raddick, M. J., Parmentier, E. M. \& Scheirer, D. S. Buoyant decompression melting: A possible mechanism for intraplate volcanism. J. Geophys. Res. 107, 2228-2242 (2002).

22. Langmuir, C. H., Klein, E. \& Plank, T. in Mantle Flow and Melt Generation at Mid-Ocean Ridges (eds Morgan, J. P., Blackman, D. K. \& Sinton, J.) 183-280 (Geophys. Monogr. Ser. Vol. 71, AGU, 1992).

23. Schmeling, H. Dynamic models of continental rifting with melt generation. Tectonophysics 480, 33-47 (2010).

24. Corti, G., van Wijk, J., Cloetingh, S. \& Morley, C. K. Tectonic inheritance and continental rift architecture: Numerical and analogue models of the East African Rift system. Tectonics 26, 1-13 (2007).

25. Rooney, T. O., Herzberg, C. \& Bastow, I. D. Elevated mantle potential temperature beneath East Africa. Geology 40, 27-30 (2011).

26. Silver, P. G., Russo, R. M. \& Lithgow-Bertelloni, C. Coupling of South American and African plate motion and plate deformation. Science 279, 60-63 (1998).

27. Furman, T. Geochemistry of East African Rift basalts: An overview. J. African Earth Sci. 48, 147-160 (2007).

28. Toomey, D. R. et al. Asymmetric mantle dynamics in the MELT region of the East Pacific Rise. Earth Planet. Sci. Lett. 200, 287-295 (2002).

29. Kendall, J. M. et al. Afar Volcanic Province within the East African Rift System Vol. 259 55-72 (The Geological Society of London, 2006).

30. Moucha, R. \& Forte, A. M. Changes in African topography driven by mantle convection. Nature Geosci. 4, 707-712 (2011).

\section{Acknowledgements}

We acknowledge financial support for personnel and data acquisition and analysis from the Natural Environment Research Council, UK (NE/E005284/1, NE/G013438/1 and NE/E007414/1) and the National Science Foundation, USA (EAR-0635789). Additional data came from the Incorporated Research Institutions for Seismology Data Management Center. We thank everyone who helped with the field work. This work would not have been possible without the continued support and collaboration from the University of Addis Ababa, for which we are very appreciative.

\section{Author contributions}

C.A.R. developed the seismic methodology, carried out imaging and modelling and wrote the paper. N.H. carried out geodynamic modelling and corresponding seismic predictions. N.H. and C.A.R. developed the interpretations and decompression melting hypotheses and made the figures. J.O.S.H. compiled data and provided advice on stations, Moho structure and migration. J.M.K. initiated the project. J.M.K., J.O.S.H., C.E., D.K., I.D.B. and M.B. provided advice on regional tectonics and geodynamics. All authors discussed results and commented on the manuscript.

\section{Additional information}

The authors declare no competing financial interests. Supplementary information accompanies this paper on www.nature.com/naturegeoscience. Reprints and permissions information is available online at www.nature.com/reprints. Correspondence and requests for materials should be addressed to C.A.R. 